OPEN ACCESS

Edited by:

Hyung-Jun Im

Seoul National University, South Korea

Reviewed by:

Weiyu Chen

Stanford University, United States

Yifan Zhang,

Shenzhen University, China

*Correspondence:

Xiaoli Lan

xiaoli_lan@hust.edu.cn;

LXL730724@hotmail.com

Specialty section:

This article was submitted to Nanoscience,

a section of the journal

Frontiers in Chemistry

Received: 29 May 2020

Accepted: 21 July 2020

Published: 07 October 2020

Citation:

Liu Q, Fang H, Gai Y and Lan X (2020) $\mathrm{pH}$-Triggered Assembly of Natural Melanin Nanoparticles for Enhanced PET Imaging. Front. Chem. 8:755 doi: $10.3389 /$ fchem.2020.00755

\section{pH-Triggered Assembly of Natural Melanin Nanoparticles for Enhanced PET Imaging}

\author{
Qingyao Liu ${ }^{1,2}$, Hanyi Fang ${ }^{1,2}$, Yongkang Gai ${ }^{1,2}$ and Xiaoli Lan ${ }^{1,2 *}$ \\ ${ }^{1}$ Department of Nuclear Medicine, Union Hospital, Tongji Medical College, Huazhong University of Science and Technology, \\ Wuhan, China, ${ }^{2}$ Hubei Province Key Laboratory of Molecular Imaging, Wuhan, China
}

Natural melanin nanoplatforms have attracted attention in molecular imaging. Natural melanin can be made into small-sized nanoparticles, which penetrate tumor sites deeply, but unfortunately, the particles continue to backflow into the blood or are cleared into the surrounding tissues, leading to loss of retention within tumors. Here, we report a pH-triggered approach to aggregate natural melanin nanoparticles by introducing a hydrolysis-susceptible citraconic amide on the surface. Triggered by $\mathrm{pH}$ values lower than 7.0, such as the tumor acid environment, the citraconic amide moiety tended to hydrolyze abruptly, resulting in both positive and negative surface charges. The electrostatic attractions between nanoparticles drove nanoparticle aggregation, which increased accumulation in the tumor site because backflow was blocked by the increased size. Melanin nanoparticles have the natural ability to bind metal ions, which can be labeled with isotopes for nuclear medicine imaging. When the melanin nanoparticles were labeled by ${ }^{68} \mathrm{Ga}$, we observed that the $\mathrm{pH}$-induced physical aggregation in tumor sites resulted in enhanced PET imaging. The $\mathrm{pH}$-triggered assembly of natural melanin nanoparticles could be a practical strategy for efficient tumor targeted imaging.

Keywords: natural melanin nanoparticles, pH-triggered aggregation, ${ }^{68} \mathrm{Ga}$ labeling, PET imaging, enhanced tumor retention

\section{INTRODUCTION}

With the continuing development of nanotechnology, there is still strong demand for the design of new nanoparticles that have the properties of biocompatibility, long circulation time, low immune response, low toxicity, and biodegradability for biomedical applications (Jiao et al., 2018; Yang et al., 2019; Ou et al., 2020). Nature has inspired scientists to mimic precise dimensional biopolymer systems that play crucial roles in the physiology of many organisms and disease processes. Great efforts have been devoted to the modification of natural nanoparticles with high applicability potential (Cormode et al., 2010; Carrera et al., 2017; Aqil et al., 2019).

Among potential nanoparticles, melanin has attracted increasing attention because of its physicochemical properties. Melanin is an endogenous pigment that is distributed widely throughout human tissues and organs such as skin, mucous membranes, retinas, gallbladder, and ovaries, making it safe for in vivo application (Watts et al., 1981). Recent investigations demonstrated that melanin could serve as a photothermal agent (Liu Y. et al., 2013; Chu et al., 2016) and a photoacoustic probe (Ju et al., 2016; Liu et al., 2018) because of its strong near-infrared light absorption and high photothermal conversion efficiency. Moreover, melanin is an effective drug delivery system that can load chemotherapeutic drugs with aromatic structures via $\pi-\pi$ stacking 
and/or hydrogen binding (Zhang et al., 2015), and the drug release can be stimulated by multiple methods, including near infrared light, $\mathrm{pH}$, and reactive oxygen species (Araújo et al., 2014; Wang et al., 2016; Kim et al., 2017). As the structure of melanin includes abundant carboxyl groups, amino groups, and phenolic hydroxyl groups, it can serve as a natural multisite metal chelating agent, making it capable of complexing many metal ions under mild conditions (Kim et al., 2012; Thaira et al., 2019). Many radionuclides are metallic elements, such as ${ }^{64} \mathrm{Cu},{ }^{89} \mathrm{Zr},{ }^{68} \mathrm{Ga},{ }^{177} \mathrm{Lu}$, and ${ }^{99 \mathrm{~m}} \mathrm{Tc}$. Much effort is required to synthesize bifunctional chelators by labeling these radionuclides and optimizing the labeling conditions (Kang et al., 2015; Gai et al., 2016, 2018). Melanin may provide a facile strategy for labeling with radiometals. Cheng's group actively chelated melanin to ${ }^{64} \mathrm{Cu}^{2+}$ and $\mathrm{Fe}^{3+}$ for PET and MRI imaging with high loading capacity and stability, indicating that melanin is a promising multimodality imaging nanoplatform (Fan et al., 2014; Hong et al., 2017).

Melanin can be made into nanoparticles with controllable sizes from a few nanometers to hundreds of nanometers (Ren et al., 2016; Amin et al., 2017; Lemaster et al., 2019). Studies have shown that small nanoparticles $(<20 \mathrm{~nm})$ can avoid macrophage recognition and penetrate tissues more deeply (Perrault et al., 2009; Liu C. et al., 2013). However, unfortunately, when small nanoparticles reach the tumor site, they continue to backflow into the bloodstream or are cleared into the surrounding tissues, decreasing retention within the tumor (Larsen et al., 2009; Zeng et al., 2016). Nanoparticles about $100 \mathrm{~nm}$ in size have been reported to have good retention but still high accumulation in the liver and pancreas before reaching the tumor, resulting in relatively low drug concentrations at the tumor site (Jain and Stylianopoulos, 2010; Albanese et al., 2012).

To overcome these limitations, we introduce a $\mathrm{pH}$ triggered approach to aggregate small-sized melanin nanoparticles ( $\mathrm{pH}-\mathrm{MNPs}$ ). The MNPs are redecorated with hydrolysis-susceptible citraconic amide, which can maintain a small size in the blood. When they reach the tumor site, spontaneous aggregation occurs in response to the tumor's acidic microenvironment. The aggregation of melanin nanoparticles cannot exceed the size of the blood vessels, and they become trapped in the extracellular matrix between cells because of their increased size, resulting in enhanced retention in the tumor site (Liu X. et al., 2013). In addition, the $\mathrm{pH}$-melanin was labeled by ${ }^{68} \mathrm{Ga}$, and the in vivo PET imaging and biodistribution profiles of ${ }^{68} \mathrm{Ga}-\mathrm{pH}-\mathrm{MNPs}$ were evaluated. We ascertained that the $\mathrm{pH}$-triggered assembly of natural melanin nanoparticles could result in enhanced PET imaging, which could be a practical strategy for efficient tumor imaging.

\section{MATERIALS AND METHODS}

\section{Materials and Reagents}

Melanin was purchased from Sigma-Aldrich. Methoxy polyethylene glycol amine (mPEG2000- $\mathrm{NH}_{2}$ ) was purchased from the Shanghai Aladdin Biochemical Technology Co., Ltd.

\section{Cell Line and Animal}

H22 mouse hepatocarcinoma cells were purchased from the American Type Culture Collection (ATCC) and cultured in standard cell medium recommended by ATCC. Male BALB/c mice (6-8 weeks, 20-22 g) were provided by the animal center of Tongji Medical College (Wuhan, China). The mice were raised at an animal facility under special pathogen-free (SPF) conditions with a $12 \mathrm{~h}$ light/dark cycle and free access to food and water. The animal study was reviewed and approved by the Laboratory Animal Management Committee of Tongji Medical College of Huazhong University of Science and Technology.

\section{Preparation of PEG-Functionalized Melanin Nanoparticles (PEG-MNPs)}

Thirty mg of the melanin granule was dissolved in $10 \mathrm{ml}$ of $\mathrm{NaOH}$ $(0.1 \mathrm{~N})$ and sonicated for $30 \mathrm{~min}$ with a bath type sonicator. Then, $90 \mathrm{mg}$ of $\mathrm{mPEG} 2000-\mathrm{NH}_{2}(\mathrm{Mw}=2,000)$ aqueous solution was dropped into the above aqueous solution and stirred with a magnetic stirrer. After vigorous stirring for $12 \mathrm{~h}$, the mixed solution was retrieved by centrifugation (MWCO-10,000, Millipore) at 4,000 rpm for $30 \mathrm{~min}$ and washed several times with deionized water.

\section{Preparation of pH-Sensitive Melanin Nanoparticles (pH-MNPs)}

Thirty mg of the melanin granule was dissolved in $10 \mathrm{ml}$ of $\mathrm{NaOH}$ $(0.1 \mathrm{~N})$ and sonicated for $30 \mathrm{~min}$ with a bath type sonicator. Then, $90 \mathrm{mg}$ of mPEG2000- $\mathrm{NH}_{2}(\mathrm{Mw}=2,000)$ and $270 \mu \mathrm{mol}$ of ethylenediamine were added into the above aqueous solution and stirred with a magnetic stirrer. After vigorous stirring for $12 \mathrm{~h}$, the mixed solution was retrieved by centrifugation (MWCO-10,000, Millipore) at 4,000 rpm for $30 \mathrm{~min}$ and washed several times with deionized water. Then, $200 \mu \mathrm{mol}$ of citraconic anhydride was added into the obtained $10 \mathrm{ml}$ of melanin aqueous solution $(1 \mathrm{mg} / \mathrm{ml}$ of water) and the $\mathrm{pH}$ was adjusted to 9.0 with $\mathrm{NaOH}(0.1 \mathrm{~N})$. After vigorous stirring for $12 \mathrm{~h}$, mPEG and the citraconic amide modified MNPs were retrieved by centrifugation (MWCO-10,000, Millipore) at 4,000 rpm for $30 \mathrm{~min}$ and washed several times with deionized water.

\section{Characterization of Melanin Nanoparticles}

The size and zeta potential of MNPs under $\mathrm{pH} 9,7.4$, and 6 were measured by a dynamic light scattering (DLS) instrument (Malvern instruments Ltd). The morphologies of MNPs were obtained under a transmission electronic microscope (TEM) at $100 \mathrm{kV}$.

\section{${ }^{68} \mathrm{Ga}^{2+}$ Radiolabeling}

${ }^{68} \mathrm{GaCl}_{2}$ was washed from a ${ }^{68} \mathrm{Ge} /{ }^{68} \mathrm{Ga}$ radionuclide generator by $4 \times 1 \mathrm{ml}$ high purity hydrochloric acid $(\mathrm{HCl}, 0.05 \mathrm{M})$, and we took the one with the highest radioactivity. One $\mathrm{ml}$ of ${ }^{68} \mathrm{GaCl}_{2}$ nearly $5 \mathrm{mCi}$ in $0.05 \mathrm{M} \mathrm{HCl}$ was added into $200 \mu \mathrm{l}$ PEG-MNPs or pH-MNPs (0.5 mg/ml of MNPs), then $0.25 \mathrm{M}$ $\mathrm{NaOAc}$ was added dropwise to adjust the $\mathrm{pH}$ to $4,5,6,7.4$, respectively and incubated at room temperature for $30 \mathrm{~min}$. The radiolabeled MNPs were purified by a PD-10 column (GE Healthcare) to remove the free ${ }^{68} \mathrm{Ga}$. The final product was 
washed out by PBS and passed through a $0.22 \mu \mathrm{m}$ Millipore filter into a sterile vial for in vivo $\mathrm{PET}$ imaging. The radiolabeling yield was evaluated by dividing the radioactivity of the purified radiolabeled MNPs by the total radioactivity added. The stability of ${ }^{68} \mathrm{Ga}$-labeled MNPs was determined in vitro by incubating in saline or human plasma at a physiologic temperature for $3 \mathrm{~h}$. An aliquot of ${ }^{68} \mathrm{Ga}$-labeled MNPs was removed at 1,2 , and $3 \mathrm{~h}$ intervals and the radiochemical purity was determined by ITLC (TLC scanner, BIOSCAN, USA). GF254 silica gel plates were used as the stationary phase and citrate buffer $(0.1 \mathrm{M})$ was used as the mobile phase.

\section{Cell Viability}

The in vitro cytotoxicity of MNPs was determined in $\mathrm{H} 22$ mouse hepatocarcinoma cells by the CCK-8 assay. H22 cells were cultured in DMEM (GIBCO, Carlsbad, CA, USA), supplemented with $10 \%$ fetal calf serum (FCS), $2 \mathrm{mmol} / \mathrm{l}$ glutamine, $100 \mathrm{U} / \mathrm{ml}$ penicillin, and $100 \mu \mathrm{g} / \mathrm{ml}$ streptomycin. Cells (5,000/well) were seeded in 96-well plates with $100 \mu \mathrm{L} /$ well medium and incubated overnight with $10 \%$ fetal bovine serum DMEM medium at $37^{\circ} \mathrm{C}$ and in an atmosphere of $5 \% \mathrm{CO}_{2}$. Cells were then cultured in the medium supplemented with different doses of PEG-MNPs and $\mathrm{pH}-\mathrm{MNP}$. The final concentrations of MNPs in the culture medium were fixed at $100,50,25,10$, and $5 \mu \mathrm{g} / \mathrm{ml}$, untreated cells were used as the control (with $100 \%$ cell viability), and the medium without cells was used as the blank. After treatment for 24 and $48 \mathrm{~h}$, respectively, the medium was removed and DMEM medium containing $10 \%$ CCK- 8 was added. After incubation for $30 \mathrm{~min}$ at $37^{\circ} \mathrm{C}$, the absorbance at $450 \mathrm{~nm}$ was measured by using an automatic enzyme standard instrument (Bio-Rad iMark).

\section{Subcutaneous Tumor Models}

The H22 cells were maintained in the ascitic form by sequential passages into the peritoneal cavities of $\mathrm{BALB} / \mathrm{c}$ mice, by weekly intraperitoneally (i.p.) transplanting $1 \times 10^{7}$ tumor cells in $0.2 \mathrm{ml}$. The ascites were collected, diluted with sterile saline, and the cell concentration was adjusted to $1 \times 10^{7} / \mathrm{ml}$. The diluted solution $(0.2 \mathrm{ml})$ was administered subcutaneously in the right shoulder of each mouse. When the tumors reached $0.5-0.8 \mathrm{~cm}$ in diameter, the tumor-bearing mice were subjected to in vivo PET imaging and biodistribution studies.

\section{Small Animal PET Imaging}

Small animal PET imaging of tumor-bearing mice was performed on a microPET-CT (TransPET Discoverist 180 system, Raycan Technology Co., Ltd, Suzhou, China). ${ }^{68}$ Ga-labeled PEG-MNPs and ${ }^{68}$ Ga-labeled pH-MNPs $(180.0 \pm 5.0 \mu \mathrm{Ci})$ were injected via the tail vein, respectively $(n=4)$. At different times after injection $(1,2$, and $3 \mathrm{~h})$, mice bearing $\mathrm{H} 22$ tumors were anesthetized with $2 \%$ isoflurane in $100 \%$ oxygen for maintenance during imaging, and placed prone near the center of the FOV of the scanner. PET/CT images were obtained with the static mode for 10 min followed by a CT scan in the normal mode. The PET images were reconstructed using the three-dimensional (3D) ordered-subsets expectation maximization (OSEM) algorithm with a voxel size of $0.5 \times 0.5 \times 0.5 \mathrm{~mm}^{3}$. CT images were reconstructed using the FDK algorithm with $256 \times 256 \times 256$ matrix. Images were displayed with software Carimas (Turku PET Center, Turku, Finland). No background correction was performed. The radioactivity uptake in the tumor and normal tissues were calculated using a region of interest (ROI) drawn over the whole organ region and expressed as a percentage of the injected radioactive dose per gram of tissue (\% ID/g).

\section{Biodistribution Studies}

The biodistribution studies were performed in H22 tumorbearing $\mathrm{BALB} / \mathrm{c}$ mice (6-8 weeks), weighing 20-22 g, which were randomly divided into six groups (five mice per group). ${ }^{68} \mathrm{Ga}$-labeled PEG-MNPs and ${ }^{68} \mathrm{Ga}$-labeled $\mathrm{pH}-\mathrm{MNPs}$ were intravenously injected through a tail vein and the mice were sacrificed at 1,2 , and $3 \mathrm{~h}$ intervals. The blood and organs of interest (e.g., brain, heart, lungs, liver, spleen, kidneys, stomach, small intestine, large intestine, muscle, bones, and tumor) were harvested, then weighed and measured using an automated gamma counter (2470 WIZARD, PerkinElmer, Norwalk CT, USA). The amount of radioactivity in each tissue sample was reported as the percentage of the injected dose per gram of tissue $(\% \mathrm{ID} / \mathrm{g})$.

\section{Statistical Analysis}

Quantitative data are expressed as means \pm standard deviation (SD). Means were compared using Student's $t$-test (two-tailed) with a $P$-value $<0.05$ indicating significance.

\section{RESULT AND DISCUSSION}

\section{Preparation and Characterization of pH-MNPs}

The design and synthetic procedures of $\mathrm{pH}-\mathrm{MNPs}$ are schematically illustrated in Figure 1. Firstly, the natural melanin was modified with $\mathrm{mPEG}-\mathrm{NH}_{2}$ and ethylenediamine to provide many terminal amine groups on the surface. Then, the primary amine groups were reacted with citraconic anhydride to form amide bonds (Figure 1). The citraconic amide moiety on the surface is selectively hydrolysis-susceptible in mildly acidic environments. Under neutral and alkaline conditions, the citraconic amide bonds are stable and maintain negative charges. Triggered by $\mathrm{pH}$ values lower than 7.0 , such as those present in tumor tissues that are often rendered acidic by hypoxia, the citraconic amide moiety tended to hydrolyze abruptly, resulting in both positive and negative surface charges as its terminal group changed from a carboxylate anion to a protonated amine group (Nam et al., 2009). The electrostatic attraction between nanoparticles drove nanoparticle aggregation (Supplementary Figure 1). The steric effect of mPEG may have hindered the electrostatic attraction, but the reduction of the surface modification of mPEG affected the water solubility of the MNPs. A ratio of ethylenediamine to mPEG of about 6 was reported to achieve a balance between steric hindrance and water solubility.

The product of each step of the synthesis was measured by the zeta potential and FT-IR spectra. In the FTIR spectrum of pristine melanin, the broad and strong bands in the 3,300 $3,400 \mathrm{~cm}^{-1}$ region were due to the $-\mathrm{OH}$ and $-\mathrm{NH}$ stretching. 


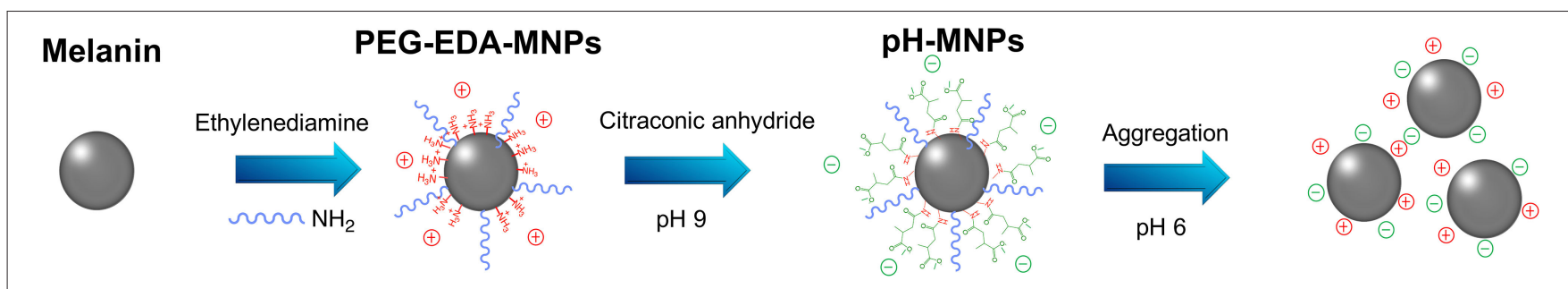

FIGURE 1 | A schematic illustration of the preparation process of the $\mathrm{pH}-\mathrm{MNPs}$.

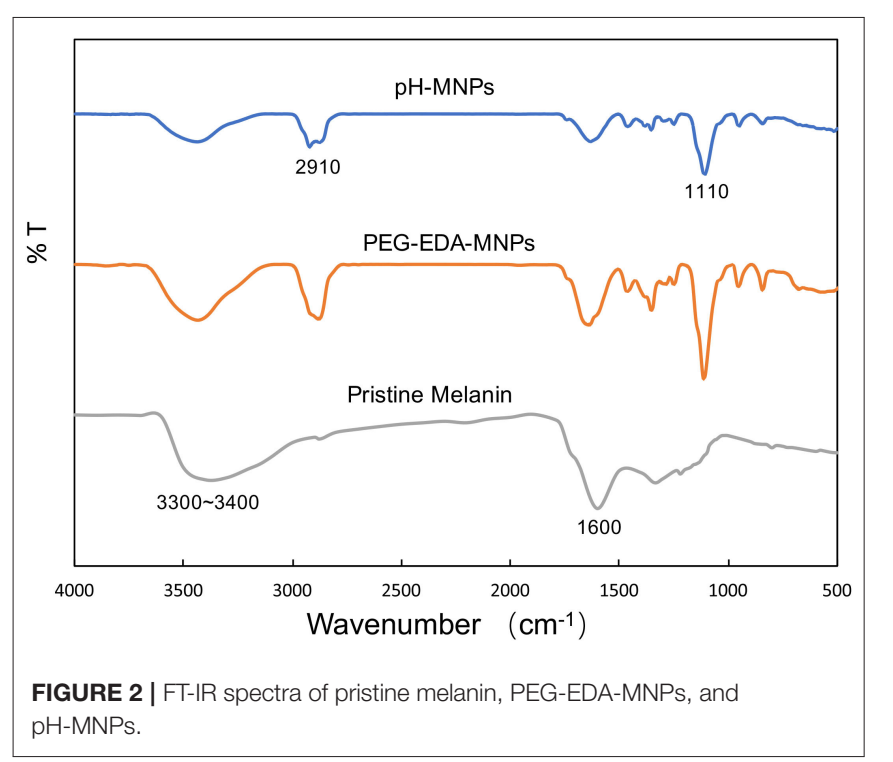

The characteristic peaks at $1,600 \mathrm{~cm}^{-1}$ were attributed to the aromatic ring $\mathrm{C}=\mathrm{C}, \mathrm{C}=\mathrm{N}$ bending, and $\mathrm{C}=\mathrm{O}$ stretching in indole and indoline structures. The FT-IR spectra detected characteristic alkyl C-H bands around $2,910 \mathrm{~cm}^{-1}$ and C-O-C stretching bands from PEG at $1,100 \mathrm{~cm}^{-1}$ after the introduction of ethylenediamine and PEG on the surface (Figure 2). Although the FT-IR spectra did not provide any additional information about the $\mathrm{pH}-\mathrm{MNPs}$, the zeta potential described a considerable change in the surface charge at each step of the surface modification (Figure 3A). Melanin itself is a negatively charged polymer, and the surface potential after the introduction of PEG remained negative $(-12.8 \pm 1.3 \mathrm{mV})$. After a reaction with a large amount of ethylenediamine, the surface charge changed from negative to positive $(6.7 \pm 0.9 \mathrm{mV})$ because of the presence of the protonated amine. The surface charge then became negative again after a reaction with citraconic anhydride, indicating successful conjugation and conversion of the amine group to a carboxylate anion. Dynamic light scattering was employed to examine the size of the MNPs after surface modification. The hydrodynamic diameters of the PEG-MNPs, PEG-EDA-MNPs, and $\mathrm{pH}$-MNPs were all $\sim 12 \mathrm{~nm}$, demonstrating no significant size differences between nanoparticle type (Figure 3B).

To characterize $\mathrm{pH}$-induced aggregation behavior in solution, we compared the stability of pristine melanin, PEG-MNPs, PEGEDA-MNPs, and $\mathrm{pH}-\mathrm{MNPs}$ under different $\mathrm{pH}$ conditions. As shown in Figure 4, pristine melanin only dissolved in the alkaline solution, while the PEG-MNPs and PEG-EDA-MNPs maintained good solubility in acidic, neutral, and alkaline conditions. However, $\mathrm{pH}-\mathrm{MNPs}$ exhibited specific aggregation in response to acidic conditions. At $\mathrm{pH} 9$ and 7.4, the solution of $\mathrm{pH}$ MNPs was clear and translucent, and at a mildly acidic $\mathrm{pH} 6$, flocculation and precipitation occurred. All of the photos were taken after the samples had been standing at room temperature for $\sim 12 \mathrm{~h}$, and the $\mathrm{pH}-\mathrm{MNPs}$ maintained a stable precipitation state, indicating that the aggregation was irreversible after complete hydrolysis. The hydrodynamic size and zeta potential of $\mathrm{pH}$-MNPs at different $\mathrm{pH}$ values were measured by dynamic light scattering (DLS), with PEG-MNPs as the control group. As shown in Supplementary Figure 2, the size of pH-MNPs was found to be $3,316 \pm 271 \mathrm{~nm}$ with a wide size distribution at $\mathrm{pH} 6$, while the particles showed a small size and narrow size distribution at $\mathrm{pH} 7.4$ and 9. In the control group, the size of PEG-MNPs did not change and maintained at $12.2 \pm 1.3 \mathrm{~nm}$ under different $\mathrm{pH}$ values. Supplementary Figure 3 showed the zeta potentials of $\mathrm{pH}-\mathrm{MNPs}$ and PEG-MNPs at different $\mathrm{pH}$ values. At $\mathrm{pH}$ value of 9 , the zeta potentials of $\mathrm{pH}-\mathrm{MNPs}$ was $-12.6 \pm 1.0 \mathrm{mV}$, and the value positively shifted to $-9.3 \pm$ $1.8 \mathrm{mV}$ under neutral conditions. After exposure to an acidic environment ( $\mathrm{pH} \mathrm{6)}$, the surface charge of $\mathrm{pH}-\mathrm{MNPs}$ shifted to a positive value $(4.9 \pm 0.3 \mathrm{mV})$, indicating the citraconic amide moieties had been hydrolyzed into protonated amine groups. PEG-MNPs also showed a trend in that the zeta potential shifted positively as the $\mathrm{pH}$ value decreased. At $\mathrm{pH} 9$, the zeta potential was $-16.4 \pm 0.7 \mathrm{mV}$, and it became $-12.8 \pm 1.3 \mathrm{mV}$ at $\mathrm{pH}$ 7.4. After exposure to $\mathrm{pH} 6$ buffer, the zeta potential positively shifted to $-9.3 \pm 0.3 \mathrm{mV}$, but remained negative. This result was due to the protonation of phenolic and amino groups of PEG-MNPs.

Dynamic light scattering (DLS) and transmission electron microscopy (TEM) were conducted to monitor the variation of particle size and morphology between different time points during the $\mathrm{pH}$-triggering process of $\mathrm{pH}$-MNPs. The TEM images in Figure 5A illustrate that the average size of the prepared $\mathrm{pH}-\mathrm{MNPs}$ was nearly $10 \mathrm{~nm}$ with a narrow size distribution, which is consistent with the results obtained by DLS. Upon $\mathrm{pH}$ triggering, the agglomeration degree of $\mathrm{pH}-\mathrm{MNPs}$ gradually grew, and the size to which the $\mathrm{pH}$ MNPs aggregated became larger. After $10 \mathrm{~min}$ of exposure to an acidic environment ( $\mathrm{pH}$ 6), the size increased to $100-160 \mathrm{~nm}$ with messy shapes observed by TEM, and DLS 
A

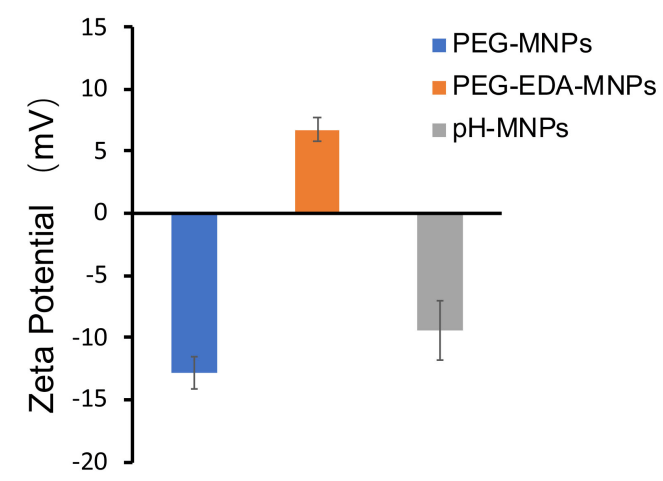

B

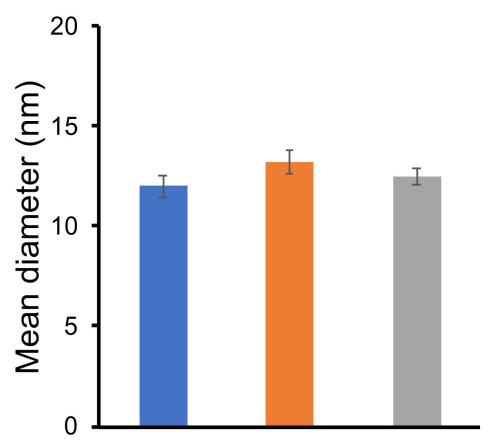

FIGURE 3 | Characteristics of MNPs. (A) Zeta potential of PEG-MNPs, PEG-EDA-MNPs, and pH-MNPs. (B) Hydrodynamic size of PEG-MNPs, PEG-EDA-MNPs, and $\mathrm{pH}-\mathrm{MNPs}$. Bars represent means $\pm \mathrm{SD}(n=3)$. All of the samples are adjusted to neutral $\mathrm{pH}$ value by buffer solution.

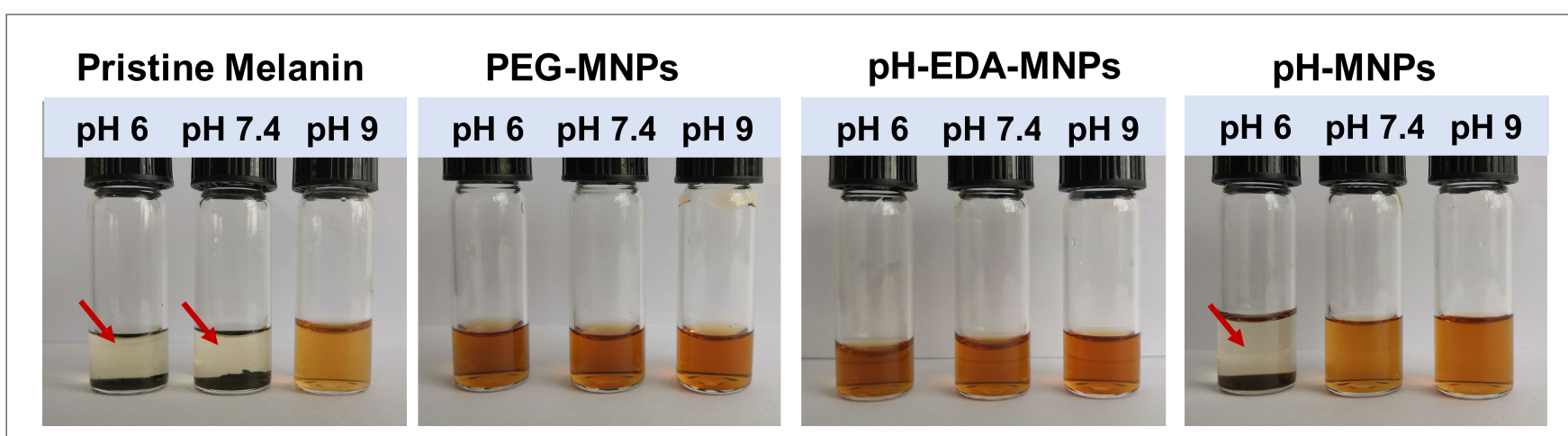

FIGURE 4 | Stability of pristine melanin, PEG-MNPs, PEG-EDA-MNPs, and pH-MNPs under different pH conditions. Standing $\sim 12 \mathrm{~h}$, photos taken of all samples. The red arrow indicates precipitation at the bottom of the bottle.

measurement showed two peaks with PDI 0.542, indicating a wide size distribution (Figure 5B). TEM measurement after $2 \mathrm{~h}$ of exposure confirmed the growth of some aggregates over time: the hydrodynamic size of $\mathrm{pH}-\mathrm{MNPs}$ continually increased to the micron level in Figure 5C, whereas such $\mathrm{pH}$-induced aggregation was not observed in PEG-MNPs (Supplementary Figure 4). These results strongly support that $\mathrm{pH}$-MNPs had the ability to undergo $\mathrm{pH}$-triggered aggregation. The aggregation of $\mathrm{pH}-\mathrm{MNPs}$ began early (within $10 \mathrm{~min}$ ), and flocculation occurred within $2 \mathrm{~h}$. This rapid $\mathrm{pH}$-response ability provides the possibility of subsequently ${ }^{68} \mathrm{Ga}$-labeling for PET imaging, which is desirable because the half-life of the ${ }^{68} \mathrm{Ga}$ nuclide is only $67.7 \mathrm{~min}$.

\section{Radiolabeling With ${ }^{68} \mathrm{Ga}$ and Stability in vitro}

Melanin has the ability to coordinate with metal ions without an additional chelator because of its inherent structure. That enables us to prepare radiometal-labeled melanin nanoparticles for molecular imaging. Furthermore, melanin can bind metal ions at a wide $\mathrm{pH}$ range because of different chelating sites on the molecule function at different $\mathrm{pH}$ ranges. Under acidic conditions, the carboxyl groups are mainly involved in binding metal ions to form complexes, whereas under alkaline conditions, the phenolic hydroxyl groups play a major role (Sarna et al., 1980). In this research, we used ${ }^{68} \mathrm{Ga}$ to radiolabel $\mathrm{pH}-\mathrm{MNPs}$ without any linker at different $\mathrm{pH}$ values. The ${ }^{68} \mathrm{Ga}-\mathrm{pH}-\mathrm{MNPs}$ exhibited high loading capacities at $\mathrm{pH} 4$ and 5 with non-decaycorrected yields of $89.6 \pm 6.2$ and $87.5 \pm 8.3 \%$, respectively (Figure 6A). As the $\mathrm{pH}$ increased, the labeling yield gradually decreased, with only $52.3 \pm 12.4 \%$ yield at $\mathrm{pH}$ 7. Considering the acid-triggered assembly of $\mathrm{pH}-\mathrm{MNPs}$, we still tried to use ${ }^{68} \mathrm{Ga}$ for labeling under neutral conditions for subsequent in vivo studies, but the labeling yield was not very high. The ${ }^{68} \mathrm{Ga}-\mathrm{pH}-\mathrm{MNPs}$ were prepared under the labeling conditions of $\mathrm{pH} 7,37^{\circ} \mathrm{C}$, and $30 \mathrm{~min}$ incubation. After purification using a PD-10 column, the radiochemical purity of the ${ }^{68} \mathrm{Ga}-\mathrm{pH}$ MNPs was determined by ITLC. On the ITLC plate, ${ }^{68} \mathrm{Ga}-\mathrm{pH}-$ MNPs remained close to the origin $(R f=0.12)$, and no free ${ }^{68} \mathrm{Ga}$ was observed at the solvent front (radiochemical purity: $>96 \%$; Supplementary Figure 5). The stability assay of ${ }^{68} \mathrm{Ga}$ $\mathrm{pH}-\mathrm{MNPs}$ in saline solution and human plasma showed that the radiochemical purity of ${ }^{68} \mathrm{Ga}-\mathrm{pH}-\mathrm{MNPs}$ remained above 

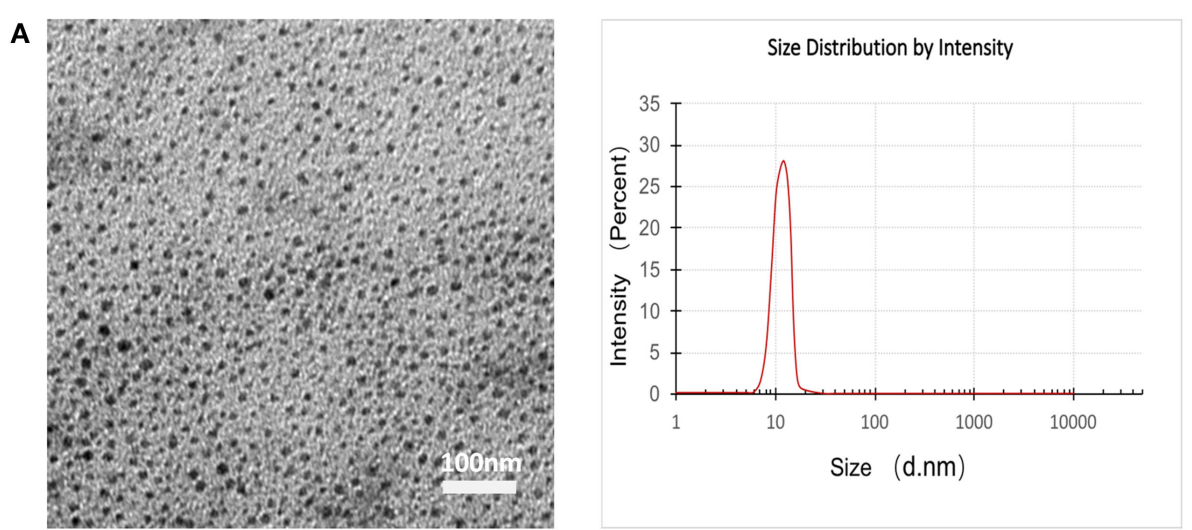

B
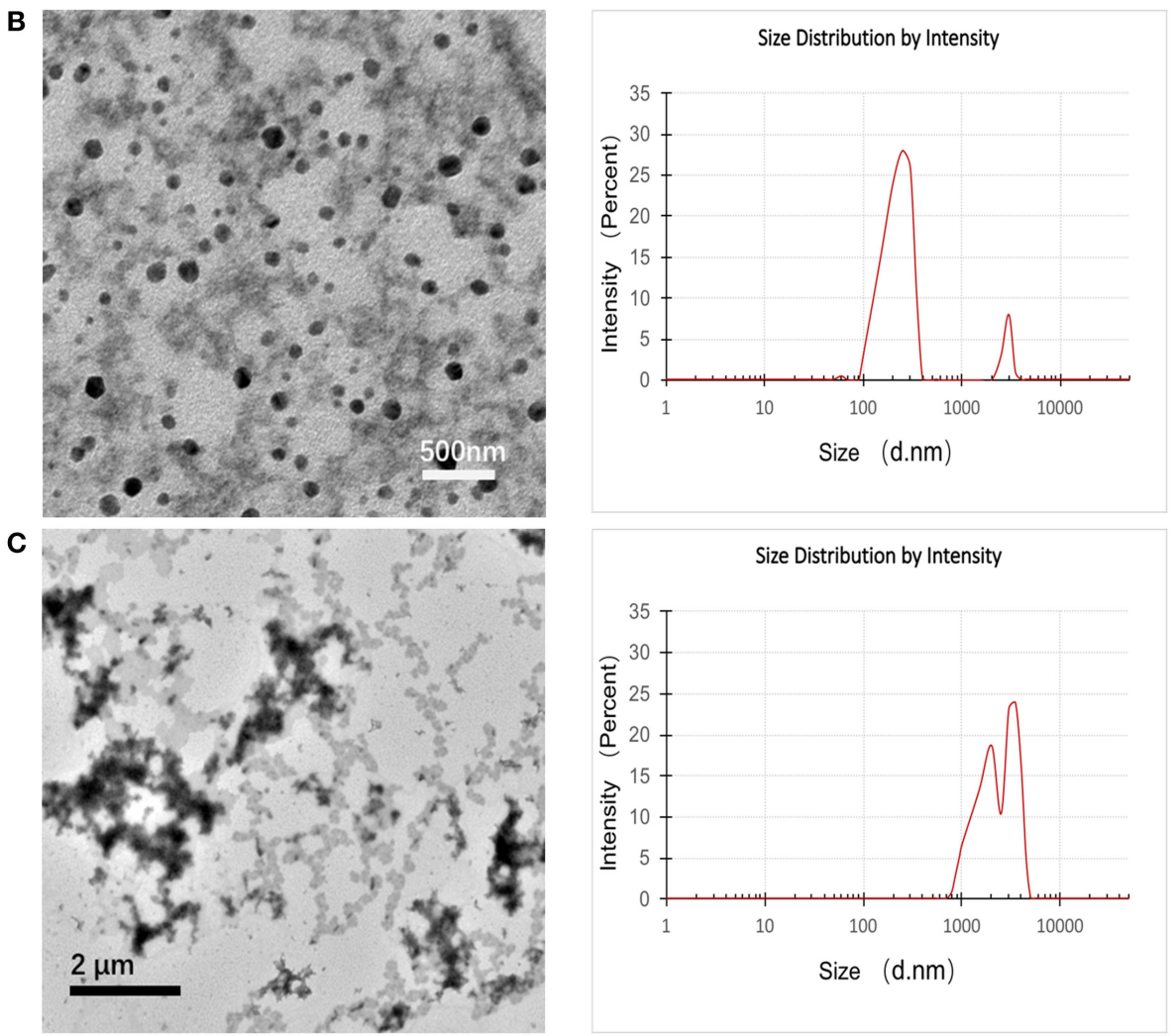

FIGURE 5 | TEM images (left) and DLS images (right) of pH-MNPs in pH 6 buffer at different elapsed times of (A) 0, (B) 10, and (C) 120 min.

95\% throughout the $3 \mathrm{~h}$ incubation period, indicating excellent stability in vitro (Figure 6B).

\section{Biocompatibility of MNPs}

To evaluate the in vitro cytotoxicity of the synthesized MNPs, CCK-8 assays were performed on H22 mouse hepatocarcinoma cells. For these assays, cultured cells were exposed to PEGMNPs and $\mathrm{pH}-\mathrm{MNPs}(5-100 \mu \mathrm{g} / \mathrm{mL})$ for 24 and $48 \mathrm{~h}$. The results showed that PEG-MNPs and $\mathrm{pH}-\mathrm{MNPs}$ did not inhibit $\mathrm{H} 22$ cell viability at any concentration at either time point (Supplementary Figure 6), indicating that the synthesized MNPs have high biocompatibility in vitro.

\section{Small Animal PET Imaging}

For PET imaging, $\sim 6.66 \mathrm{MBq}(180 \mu \mathrm{Ci})$ of ${ }^{68} \mathrm{Ga}-\mathrm{pH}-\mathrm{MNPs}$ and ${ }^{68} \mathrm{Ga}$-PEG-MNPs were injected intravenously into H22 tumorbearing mice. At different time points after injection (1, 2, and $3 \mathrm{~h}$ ), tomographic images were acquired. Figure 7 shows representative decay-corrected whole-body images. A stronger PET signal in the tumor was observed for ${ }^{68} \mathrm{Ga}-\mathrm{pH}-\mathrm{MNPs}$ than ${ }^{68} \mathrm{Ga}$-PEG-MNPs at all time points. The difference in tumor accumulation when ${ }^{68}$ Ga-PEG-MNPs are employed may be due to backflow into the bloodstream over time. In contrast, the $\mathrm{pH}$ triggered aggregation of ${ }^{68} \mathrm{Ga}-\mathrm{pH}-\mathrm{MNPs}$, which can be trapped in tumor tissue, led to enhanced PET imaging. In addition 

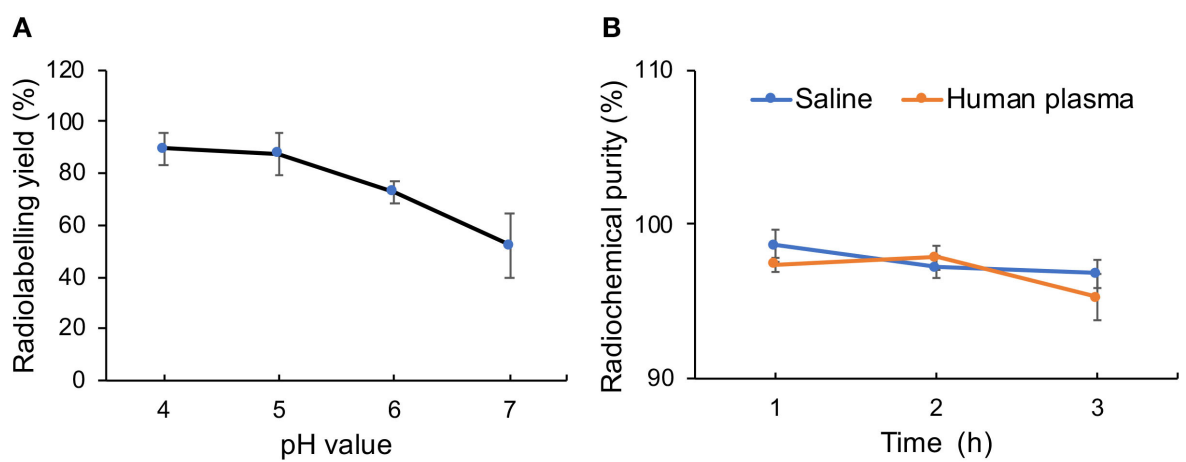

FIGURE 6 | Characterization of radiolabeling with ${ }^{68} \mathrm{Ga}$. (A) Radiolabeling yield of ${ }^{68} \mathrm{Ga}-\mathrm{pH}-\mathrm{MNPs}$ at different $\mathrm{pH}$ and (B) stability of ${ }^{68} \mathrm{Ga}-$ labeled MNPs incubated in saline or human plasma for 1,2 , and $3 \mathrm{~h}$.

A

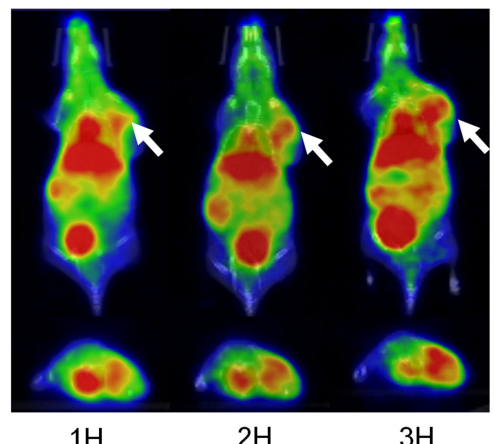

B

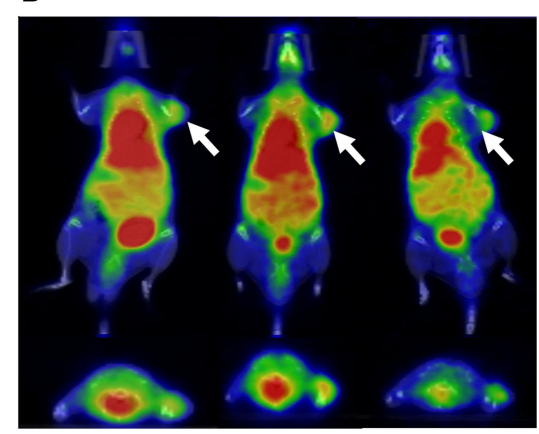

$1 \mathrm{H}$
$7 \% \mathrm{ID} / \mathrm{g}$

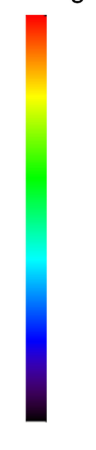

FIGURE 7 | The overlaying of the PET and CT images of H22 tumors acquired at 1, 2, and $3 \mathrm{~h}$ after the intravenous injection of (A) ${ }^{68} \mathrm{Ga}-\mathrm{pH}-\mathrm{MNPS}$ and (B) ${ }^{68} \mathrm{Ga}-\mathrm{PEG}-\mathrm{MNPs}$. Representative decay-corrected coronal and transaxial are displayed on the top and bottom respectively. The white arrow indicates tumor site.

to that within the tumor, moderate activity accumulation was found in the liver because nanoparticles are easily captured by the reticuloendothelial system. The heart was visible, perhaps because of the circulation of small-sized melanin nanoparticles in the blood. Quantitative analysis of three-dimensional regions of interest over multiple image slices revealed that the tumor uptake of ${ }^{68} \mathrm{Ga}$-pH-MNPs was up to 2.4 times higher than that of ${ }^{68} \mathrm{Ga}$ PEG-MNPs at $3 \mathrm{~h}$ post-injection $(4.47 \pm 0.73$ vs. $1.87 \pm 0.56 \%$ ID/g, respectively, $p<0.01$; Supplementary Figure 7).

\section{Biodistribution Study}

The biodistribution results are shown in Figure 8. The radioactivity in blood gradually decreased over time, indicating that ${ }^{68} \mathrm{Ga}-\mathrm{pH}-\mathrm{MNPs}$ were gradually cleared from circulation (Figure 8A). The liver showed the highest uptake among the tissues studied $(7.47 \pm 0.76 \% \mathrm{ID} / \mathrm{g}$ at $1 \mathrm{~h})$, and then the level reduced gradually but was still prominent at $3 \mathrm{~h}$ post-injection $(4.51 \pm 0.72 \% \mathrm{ID} / \mathrm{g})$. Relatively lower activity accumulation was observed in the spleen and kidney. The ${ }^{68} \mathrm{Ga}-\mathrm{pH}-\mathrm{MNPs}$ was mainly cleared through the hepatobiliary system. The tumor uptake of ${ }^{68} \mathrm{Ga}-\mathrm{pH}-\mathrm{MNPs}$ consistently increased, and the enhanced retention was maintained throughout all time points $(2.54 \pm 0.38,3.35 \pm 0.13$, and $3.86 \pm 0.25 \% \mathrm{ID} / \mathrm{g}$ at 1 ,
2 , and $3 \mathrm{~h}$ p.i., respectively). In contrast, the tumor uptake of ${ }^{68} \mathrm{Ga}-\mathrm{PEG}-\mathrm{MNPs}$ decreased from $2.14 \pm 0.38 \% \mathrm{ID} / \mathrm{g}$ ( $1 \mathrm{~h}$ p.i.) to $1.34 \pm 0.25 \% \mathrm{ID} / \mathrm{g}$ ( $3 \mathrm{~h}$ p.i.) (Figure $8 \mathrm{~B}$ ). The results were consistent with the PET images above. The tumor-to-muscle ratio of ${ }^{68} \mathrm{Ga}-\mathrm{pH}-\mathrm{melanin}$ increased significantly from 4.74 \pm 0.76 at $1 \mathrm{~h}$ p.i. to $29.30 \pm 5.64$ at $3 \mathrm{~h}$ p.i., a much greater increase than that of ${ }^{68} \mathrm{Ga}-\mathrm{PEG}-\mathrm{melanin}(2.88 \pm 0.74$ at $3 \mathrm{~h}$ p.i.). However, the tumor-to-blood ratio was relatively low, probably because nanoparticles were still circulating in the blood (Supplementary Table 1). Therefore, the pH-MNPs can achieve enhanced tumor retention for PET imaging.

\section{CONCLUSIONS}

In this work, we have successfully designed and prepared natural melanin nanoparticles that can form aggregates in response to $\mathrm{pH}$ changes. Under mildly acidic conditions, the $\mathrm{pH}-\mathrm{MNPs}$ began to aggregate and became trapped by their increasing size, resulting in enhanced tumor retention. We also demonstrated that the $\mathrm{pH}-$ MNPs could be successfully radiolabeled with the ${ }^{68} \mathrm{Ga}$ nuclide in a $\mathrm{pH}$-neutral environment by simple mixing. The resultant ${ }^{68} \mathrm{Ga}-\mathrm{pH}-\mathrm{MNPs}$ exhibited enhanced PET imaging, which could 


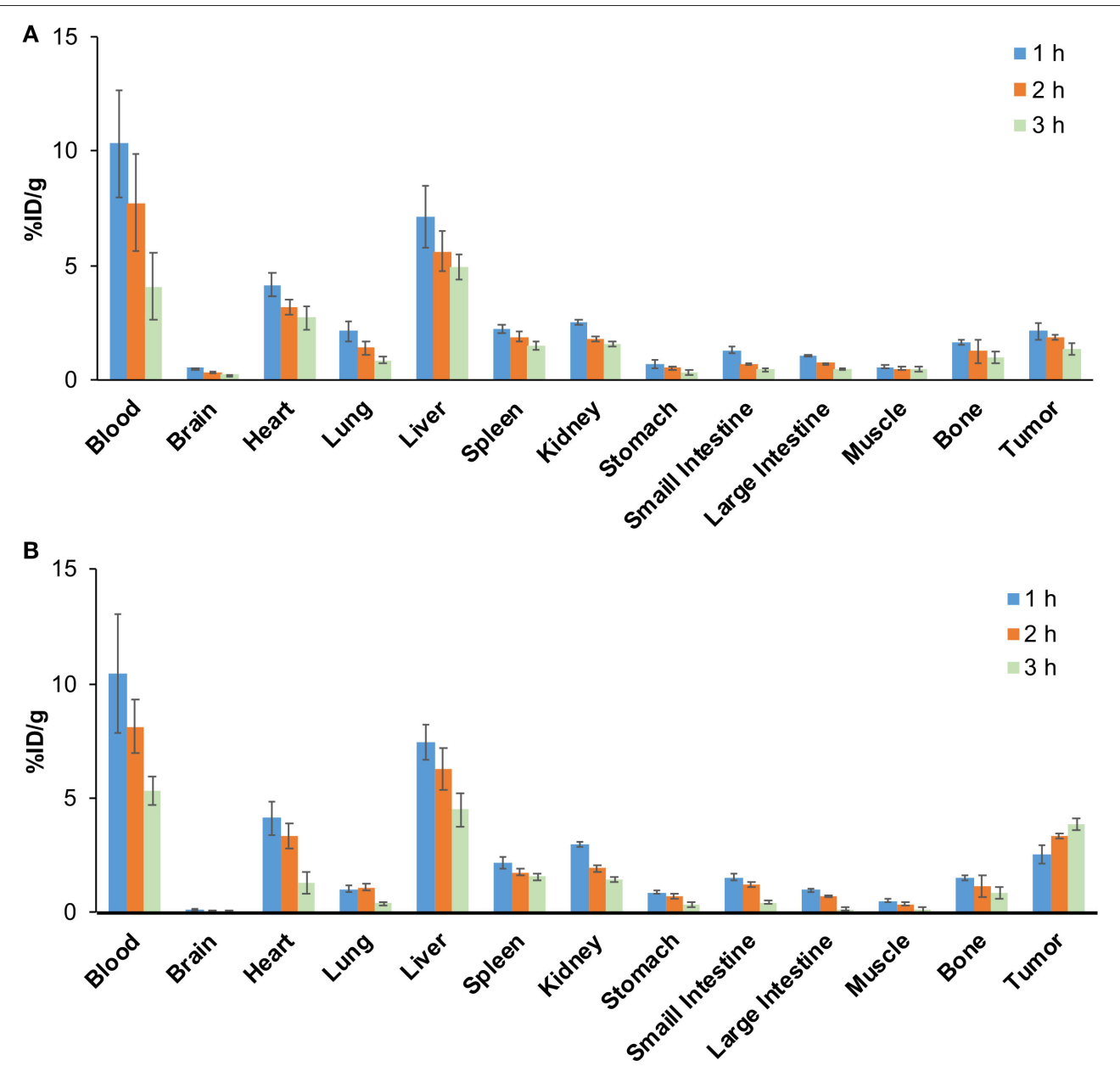

FIGURE 8 | Biodistribution study of $\mathrm{H} 22$ tumor-bearing mice $(n=5)$ at different time points in $(\mathbf{A})$ the ${ }^{68} \mathrm{Ga}-\mathrm{PEG}-\mathrm{MNPs}$ group and $(\mathbf{B})$ the ${ }^{68} \mathrm{Ga-pH}-\mathrm{MNPs}$ group.

provide a promising strategy for molecular imaging and future clinical trials.

\section{DATA AVAILABILITY STATEMENT}

The raw data supporting the conclusions of this article will be made available by the authors, without undue reservation.

\section{ETHICS STATEMENT}

The animal study was reviewed and approved by Laboratory Animal Management Committee of Tongji Medical College of Huazhong University of Science and Technology.

\section{AUTHOR CONTRIBUTIONS}

QL conceived the idea and supervised the research work overall. $\mathrm{HF}$ and $\mathrm{YG}$ contributed to the experiment methods and data analysis. QL wrote the manuscript and drew all the figures. YG came up with ideas for the manuscript. XL contributed to the revision of the paper. All authors contributed to the article and approved the submitted version.

\section{FUNDING}

This work was supported by the National Natural Science Foundation of China (No. 81501532).

\section{ACKNOWLEDGMENTS}

We thank Richard Lipkin, PhD, from Liwen Bianji, Edanz Group China (www.liwenbianji.cn/ac), for edited the English text of a draft of this manuscript.

\section{SUPPLEMENTARY MATERIAL}

The Supplementary Material for this article can be found online at: https://www.frontiersin.org/articles/10.3389/fchem. 2020.00755/full\#supplementary-material 


\section{REFERENCES}

Albanese, A., Tang, P. S., and Chan, W. C. (2012). The effect of nanoparticle size, shape, and surface chemistry on biological systems. Annu. Rev. Biomed. Eng. 14, 1-16. doi: 10.1146/annurev-bioeng-071811-150124

Amin, D. R., Sugnaux, C., Lau, K. H. A., and Messersmith, P. B. (2017). Size control and fluorescence labeling of polydopamine melanin-mimetic nanoparticles for intracellular imaging. Biomimetics 2:17. doi: 10.3390/biomimetics2030017

Aqil, F., Munagala, R., Jeyabalan, J., Agrawal, A. K., Kyakulaga, A.-H., Wilcher, S. A., et al. (2019). Milk exosomes-natural nanoparticles for siRNA delivery. Cancer Lett. 449, 186-195. doi: 10.1016/j.canlet.2019.02.011

Araújo, M., Viveiros, R., Correia, T. R., Correia, I. J., Bonifácio, V. D., Casimiro, T., et al. (2014). Natural melanin: a potential $\mathrm{pH}$-responsive drug release device. Int. J. Pharm. 469, 140-145. doi: 10.1016/j.ijpharm.2014.04.051

Carrera, P., Espinoza-Montero, P. J., Fernández, L., Romero, H., and Alvarado, J. (2017). Electrochemical determination of arsenic in natural waters using carbon fiber ultra-microelectrodes modified with gold nanoparticles. Talanta 166, 198-206. doi: 10.1016/j.talanta.2017.01.056

Chu, M., Hai, W., Zhang, Z., Wo, F., Wu, Q., Zhang, Z., et al. (2016). Melanin nanoparticles derived from a homology of medicine and food for sentinel lymph node mapping and photothermal in vivo cancer therapy. Biomaterials 91, 182-199. doi: 10.1016/j.biomaterials.2016.03.018

Cormode, D. P., Jarzyna, P. A., Mulder, W. J., and Fayad, Z. A. (2010). Modified natural nanoparticles as contrast agents for medical imaging. Adv. Drug Deliv. Rev. 62, 329-338. doi: 10.1016/j.addr.2009.11.005

Fan, Q., Cheng, K., Hu, X., Ma, X., Zhang, R., Yang, M., et al. (2014). Transferring biomarker into molecular probe: melanin nanoparticle as a naturally active platform for multimodality imaging. J. Am. Chem. Soc. 136, 15185-15194. doi: $10.1021 / \mathrm{ja} 505412 \mathrm{p}$

Gai, Y., Sun, L., Hui, W., Ouyang, Q., Anderson, C. J., Xiang, G., et al. (2016). New bifunctional chelator p-SCN-PhPr-NE3TA for copper-64: synthesis, peptidomimetic conjugation, radiolabeling, and evaluation for PET imaging. Inorg. Chem. 55, 6892-6901. doi: 10.1021/acs.inorgchem.6b00395

Gai, Y., Sun, L., Lan, X., Zeng, D., Xiang, G., and Ma, X. (2018). Synthesis and evaluation of new bifunctional chelators with Phosphonic acid arms for Gallium-68 based PET imaging in melanoma. Bioconjug. Chem. 29, 3483-3494. doi: 10.1021/acs.bioconjchem.8b00642

Hong, S. H., Sun, Y., Tang, C., Cheng, K., Zhang, R., Fan, Q., et al. (2017). Chelator-free and biocompatible melanin nanoplatform with facile-loading gadolinium and copper-64 for bioimaging. Bioconjug. Chem. 28, 1925-1930. doi: 10.1021 /acs.bioconjchem.7b00245

Jain, R. K., and Stylianopoulos, T. (2010). Delivering nanomedicine to solid tumors. Nature Rev. Clin. Oncol. 7:653. doi: 10.1038/nrclinonc.2010.139

Jiao, M., Zhang, P., Meng, J., Li, Y., Liu, C., Luo, X., et al. (2018). Recent advancements in biocompatible inorganic nanoparticles towards biomedical applications. Biomater. Sci. 6, 726-745. doi: 10.1039/C7BM01020F

Ju, K.-Y., Kang, J., Pyo, J., Lim, J., Chang, J. H., and Lee, J.-K. (2016). pH-Induced aggregated melanin nanoparticles for photoacoustic signal amplification. Nanoscale 8, 14448-14456. doi: 10.1039/C6NR02294D

Kang, C. S., Chen, Y., Lee, H., Liu, D., Sun, X., Kweon, J., et al. (2015). Synthesis and evaluation of a new bifunctional NETA chelate for molecular targeted radiotherapy using $90 \mathrm{Y}$ or $177 \mathrm{Lu}$. Nucl. Med. Biol. 42, 242-249. doi: 10.1016/j.nucmedbio.2014.10.004

Kim, D. J., Ju, K.-Y., and Lee, J.-K. (2012). The synthetic melanin nanoparticles having an excellent binding capacity of heavy metal ions. Bull. Korean Chem. Soc. 33, 3788-3792. doi: 10.5012/bkcs.2012.33.11.3788

Kim, M. A., Do Yoon, S., and Lee, C.-M. (2017). A drug release system induced by near infrared laser using alginate microparticles containing melanin. Int. J. Biol. Macromol. 103, 839-844. doi: 10.1016/j.ijbiomac.2017.05.139

Larsen, E. K., Nielsen, T., Wittenborn, T., Birkedal, H., Vorup-Jensen, T., Jakobsen, M. H., et al. (2009). Size-dependent accumulation of PEGylated silane-coated magnetic iron oxide nanoparticles in murine tumors. ACS Nano 3, 1947-1951. doi: $10.1021 / \mathrm{nn} 900330 \mathrm{~m}$

Lemaster, J. E., Jeevarathinam, A. S., Kumar, A., Chandrasekar, B., Chen, F., and Jokerst, J. V. (2019). Synthesis of ultrasmall synthetic melanin nanoparticles by UV irradiation in acidic and neutral conditions. ACS Appl. Bio Mater. 2, 4667-4674. doi: 10.1021/acsabm.9b00747

Liu, C., Gao, Z., Zeng, J., Hou, Y., Fang, F., Li, Y., et al. (2013). Magnetic/upconversion fluorescent NaGdF4: Yb, Er nanoparticle-based dualmodal molecular probes for imaging tiny tumors in vivo. ACS Nano 7 , 7227-7240. doi: $10.1021 / \mathrm{nn} 4030898$

Liu, M., Wang, Y., Li, M., Feng, H., Liu, Q., Qin, C., et al. (2018). Using tyrosinase as a tri-modality reporter gene to monitor transplanted stem cells in acute myocardial infarction. Exp. Mol. Med. 50, 1-10. doi: 10.1038/s12276-018-0088-z

Liu, X., Chen, Y., Li, H., Huang, N., Jin, Q., Ren, K., et al. (2013). Enhanced retention and cellular uptake of nanoparticles in tumors by controlling their aggregation behavior. ACS Nano 7, 6244-6257. doi: 10.1021/nn402201w

Liu, Y., Ai, K., Liu, J., Deng, M., He, Y., and Lu, L. (2013). Dopaminemelanin colloidal nanospheres: an efficient near-infrared photothermal therapeutic agent for in vivo cancer therapy. Adv. Mater. 25, 1353-1359. doi: 10.1002/adma.201204683

Nam, J., Won, N., Jin, H., Chung, H., and Kim, S. (2009). pH-induced aggregation of gold nanoparticles for photothermal cancer therapy. J. Am. Chem. Soc. 131, 13639-13645. doi: 10.1021/ja902062j

Ou, J., Liu, K., Jiang, J., Wilson, D. A., Liu, L., Wang, F., et al. (2020). Micro-/nanomotors toward biomedical applications: the recent progress in biocompatibility. Small 16:1906184. doi: 10.1002/smll.201906184

Perrault, S. D., Walkey, C., Jennings, T., Fischer, H. C., and Chan, W. C. (2009). Mediating tumor targeting efficiency of nanoparticles through design. Nano Lett. 9, 1909-1915. doi: 10.1021/nl900031y

Ren, X., Zheng, R., Fang, X., Wang, X., Zhang, X., Yang, W., et al. (2016). Red blood cell membrane camouflaged magnetic nanoclusters for imaging-guided photothermal therapy. Biomaterials 92, 13-24. doi: 10.1016/j.biomaterials.2016.03.026

Sarna, T., Froncisz, W., and Hyde, J. S. (1980). Cu2+ probe of metalion binding sites in melanin using electron paramagnetic resonance spectroscopy: II. Natural melanin. Arch. Biochem. Biophys. 202, 304-313. doi: 10.1016/0003-9861(80)90431-2

Thaira, H., Raval, K., Manirethan, V., and Balakrishnan, R. M. (2019). Melanin nano-pigments for heavy metal remediation from water. Sep. Sci. Technol. 54, 265-274. doi: 10.1080/01496395.2018.1443132

Wang, X., Zhang, J., Wang, Y., Wang, C., Xiao, J., Zhang, Q., et al. (2016). Multi-responsive photothermal-chemotherapy with drug-loaded melaninlike nanoparticles for synergetic tumor ablation. Biomaterials 81, 114-124. doi: 10.1016/j.biomaterials.2015.11.037

Watts, K. P., Fairchild, R. G., Slatkin, D. N., Greenberg, D., Packer, S., Atkins, H. L., et al. (1981). Melanin content of hamster tissues, human tissues, and various melanomas. Cancer Res. 41, 467-472.

Yang, G., Phua, S. Z. F., Bindra, A. K., and Zhao, Y. (2019). Degradability and clearance of inorganic nanoparticles for biomedical applications. Adv. Mater. 31:1805730. doi: 10.1002/adma.201805730

Zeng, J., Cheng, M., Wang, Y., Wen, L., Chen, L., Li, Z., et al. (2016). pH-responsive Fe (III)-gallic acid nanoparticles for in vivo photoacousticimaging-guided photothermal therapy. Adv. Healthc. Mater. 5, 772-780. doi: 10.1002/adhm.201500898

Zhang, R., Fan, Q., Yang, M., Cheng, K., Lu, X., Zhang, L., et al. (2015). Engineering melanin nanoparticles as an efficient drug-delivery system for imaging-guided chemotherapy. Adv. Mater. 27, 5063-5069. doi: 10.1002/adma.201502201

Conflict of Interest: The authors declare that the research was conducted in the absence of any commercial or financial relationships that could be construed as a potential conflict of interest.

Copyright (๑) 2020 Liu, Fang, Gai and Lan. This is an open-access article distributed under the terms of the Creative Commons Attribution License (CC BY). The use, distribution or reproduction in other forums is permitted, provided the original author(s) and the copyright owner(s) are credited and that the original publication in this journal is cited, in accordance with accepted academic practice. No use, distribution or reproduction is permitted which does not comply with these terms. 